http://dx.doi.org/10.4314/gjl.v5i1.62

\title{
A LINGUISTIC DESCRIPTION OF THE LANGUAGE OF GHANAIAN NEWSPAPERS: IMPLICATIONS FOR THE READABILITY, COMPREHENSIBILITY AND INFORMATION FUNCTION OF THE GHANAIAN PRESS
}

\author{
Modestus Fosu
}

\begin{abstract}
This paper investigates the readability and comprehensibility of English language newspapers in Ghana. It attempts a structural description of the language of the newspapers to explore implications thereof regarding the information function of the Ghanaian press. The study employed a research design that triangulated methods and findings from corpus linguistics and readability studies using front-page stories of four influential national newspapers of the country. The research established that the language used to communicate socio-political news to readers is complex and could be potentially difficult for many readers. The significant implication is that the newspapers may be largely ineffective in transmitting information directly to a wide spectrum of readers for socio-political benefits. This could mean, importantly, that the press may not be performing its information function well. Consequently, the paper makes a case for the press to use relatively readable and comprehensible language to broaden direct access to newspaper messages in the country.
\end{abstract}

Keywords: Ghanaian newspapers, language style, complexity, readability, information flow

\section{Introduction}

This study investigates language use in Ghanaian journalism. It attempts to provide a description of aspects of the writing style of quality Ghanaian newspapers to inform implications for the readability, comprehensibility and information function of the newspapers in Ghana's democracy. This study begins with the premise that the writing style or linguistic choices play a crucial role in the readability and comprehensibility of newspapers. In this study, readability refers to the ease of 
comprehending a text due to the style of writing (Klare 1963, cited in DuBay 2004: 3), while comprehensibility means the "potential for a text to be understood" (Rock 2007: 14). These two concepts are obviously related, and the use of one may imply or include the other. Writing style here implies the lexical and syntactic elements used to construct news reports.

The importance of this study lies in the remarkable fact that almost all the Ghanaian national quality newspapers continue to be published in English. This highlights the language of such publications for scrutiny within the second language context of its occurrence. This is because English occurs in Ghana as an official language among over sixty other (indigenous) languages (Obeng 1997; Guerini 2007), and the ability to write and read the language depends on formal educational attainment. Thus, the relative complexity or otherwise of the language determines who among the educated class (from primary to tertiary educational levels) could easily read and understand the newspapers' language.

The study begins with a position that the language of most Ghanaian newspapers is complex lexically and syntactically, and that this could hinder the readability and comprehensibility of the newspapers. Complexity in this study refers to the occurrence of vocabulary and sentence-structure elements in a text in a manner that could undermine information transmission and thereby cause comprehension difficulties for some readers (Just and Carpenter 1992; Hess and Biggam 2004; McNamara et al. 2010). In the context of Ghana, not just as a developing country but also as an emerging democracy, issues relating to the ability of the press to communicate with its audience are vitally important. The crucial point is that limitations on citizens' comprehension of news information are likely to affect informed political participation and thereby obstruct genuine democratic function in the country. Thus, important questions that cannot be ignored and which this study strives to address include the following: How may the language of Ghanaian newspapers be described structurally? To what extent can the writing style of the newspaper enhance or inhibit the readability and comprehensibility of stories? What could be the fallouts of the above questions to the information function of the press?

\section{The press and its informative role in Ghana}

The epistemological underpinnings of the study are in part normatively located in the responsibility of the press (real or imagined) in a democratic society (McQuail 2005; Christians et al. 2009). The expectation highlighted in this research is that the Ghanaian press ought to reach a broad section of Ghanaian readers with socio-political information. Thus, the study interrogates the extent to which the press could be effective in directly reaching and possibly influencing its readers. The argument is that the effectiveness of the press goes beyond merely producing and circulating news 
information. One way in which the effectiveness of the press may be meaningfully assessed is to discover the extent to which the newspapers' messages are readable and understandable to consumers. This study has therefore adopted an optimistic view regarding the role of the press in Ghana despite the fact that conditions in which the contemporary press operates predispose it to various interests and practices, some of which could harm democracy and/or society. Writing on the British press, Conboy (2007: 12), an expert in journalism studies and language of news, observes that:

More than any other media form, the newspaper has an explicitly normative role in how we see the world. Our news is our world to the extent that it contributes enormously to our understanding of what happens beyond our everyday experiences.

News from newspapers in Ghana may not be as pervasive as it is in the UK, but the normative picture portrayed above is relevant to the Ghanaian situation. The optimistic view is based on an understanding of the history and role of the Ghanaian press and the various changes that have occurred in the Ghanaian society and (media) economy. The media environment in Ghana in recent times has radically transformed, following the return to constitutional democracy in 1992. The rigid state controls and repressive regulations against the media during the previous autocratic regimes that dominated a greater part of post-independence Ghana gave way to continuous liberalisation of the economy and democratic institutions, including the mass media. Thus, in the past sixteen years, especially with the repeal of the criminal libel law (see section 112 of the Criminal Code of Ghana 1960) in 2001, the media scene has been greatly enhanced and continues to experience improving levels of freedom leading to massive expansion in private participation and ownership within the mass media industry.

Historically and socio-politically, the Ghanaian press has been an important source of information and/or persuasion to mobilise people toward popular political actions (Gasu 2009). The printed press has been celebrated not only for rallying indigenous people for the independence struggles during colonialism, but also for leading the fight for freedom of expression and democracy during the dark days of dictatorship in Ghana (Bourgault 1995; Asante 1996; Anokwa 1997; Karikari 1998). In recent years, the press has been seen as publicising the different contending interests, ideas, parties, social groups, and persons involved in the country's periodic general multi-party elections (Dzisah 2008). The belief then is that the newspapers reach and considerably furnish people with socio-political information and knowledge.

However, this idea about the press's influence appears to come largely from a simplistic view of the relationship between the press and audiences. Most researchers 
and media watchers seem to share the belief that the press effectively transmits information to the people once issues are raised in publications and people are seen reading newspapers. Such a conclusion fails to consider the possible struggles, tensions and negotiations that could underpin the newspaper consumption process.

\section{The problem}

Indeed, the extent to which the Ghanaian press, through its use of language, is helping or inhibiting audiences to access information is yet to be empirically known. I consider this a serious research gap because language is central to the effective functioning of the press since the press makes information available to society through language. While non-literate Ghanaians are certainly proscribed from primary information in newspapers, most educated Ghanaians who are the notional targets of the press have been found to depend on the press for local and foreign information (Ansu-Kyeremeh and Gadzekpo 1996; Amankwah 2010). Up to 30\% of Ghanaians are said to read newspapers (BBC World Trust 2006).

However, concerns have been raised over the years about the readability and comprehensibility of the press. Writing on the democratisation of the media in Africa and focusing on the Ghanaian media, Boafo (1987: 27) observed that:

In terms of readability, the content of the newspapers is generally presented in style and language, which are much above the reading and comprehension levels of the average literate Ghanaian, the elementary school-educated reader. [The elementary school is equivalent and similar to the JHS of today.]

This observation was made almost three decades ago, but the belief persists even today. In a recent ethnographically-focused study, Hasty (2005: 58) re-echoes that the Ghanaian press uses "Big English". The writer's further description of the vocabulary of the press as unwieldy, bulky, officious, authoritarian, and so on, suggests that the language of the press could pose meaning problems, not only to people with low education, but also across the entire educational system of Ghana. However, without any specific empirical support, these observations have remained anecdotal opinions leaving many questions unanswered.

Research to date on the issue in Ghana has focused largely on error analyses and sensational use of language, except Denkabe and Gadzekpo (1996) and Denkabe et al. (1997), which perhaps offer some efforts, albeit based on intuition, at dealing with the issue of newspaper readability in Ghana. Therefore, this current study empirically interrogates some specific linguistic characteristics of Ghanaian newspapers to find out 
the extent to which they contribute to the complexity or otherwise of the language and how this could affect information acquisition. Findings from this research should help in assessing empirically the effectiveness of the press as far as readers' easy access to information is concerned. If critical issues concerning the readability of Ghanaian newspapers are not investigated, language-based issues such as ideology, hegemony, framing and representation, power, as well as notions of the role of the press in society would be largely assumed and uninformed.

\section{The linguistic issues: Applied linguistics, readability studies and text complexity}

The field of applied linguistics and readability studies have produced extensive studies on language or text complexity and readability. The majority of studies in applied linguistics have identified different lexical and syntactic elements as potential causes of text complexity (see Richards and Rogers 1986; Kletzien 1991; Just and Carpenter 1992; Nation and Coady 1998; Read 2000; Hudson 2007; McNamara et al. 2010; Lu 2011; Guo et al. 2011). The general suggestion from these studies is that limited vocabulary knowledge, the inability to understand words in the context of a sentence and text, is connected with difficulty in reading and comprehension. The writers identify abstract words, and specialised/technical vocabulary (jargon) as potential causes of text complexity and reading difficulties.

Writers argue that syntactic elements also blend with lexis in various ways to make a text difficult. Factors such as the occurrences and nature of clauses and subordination in a sentence and text, passive constructions, number of words before the main verb, embedded structures within clauses, and length of linguistic structures are potential causes of text complexity (McNamara et al. 2010; Norris and Ortega 2009). McNamara et al. (2010: 62) explain that, "if the syntax of a sentence is complex, higher demands are placed on working memory processing," thereby causing readability challenges.

Readability studies, which peaked in the late 1940s, have been generally concerned with linguistic factors affecting the ease or difficulty of reading and comprehending text (DuBay 2004; Hulden 2004; Pitler and Nenkova, n.d.). The motivation was initially to evolve readability formula tools in some Western countries to help educationists and textbook writers to objectively measure reading materials and precisely ascertain what language style would most benefit readers (Hulden 2004). The concern later extended to reading activities outside of the school environment such as the readability of news stories. Consequently, various studies eventually started producing readability formulae to help measure the readability level of texts (DuBay 2004). 
These studies identify lexical (vocabulary) and syntactic (word formation and sentence structure) combinations as potentially predisposing text to complexity. But which specific linguistic elements are most likely to cause the challenge? Studies have identified nominalisations and Latinate expressions as vocabulary items whose overuse could challenge readability as they carry abstract ideas and are largely unfamiliar (Biber et al. 1999; Russell 2001). These scholars add that the use of an impersonal tone in the form of passive constructions and jargon, among others, could also make a text formal and relatively complex. Dagut and Laufer (1985), Laufer and Eliasson (1993), and Liao and Fukuya (2002) have identified phrasal verbs as a potential source of reading difficulty especially in L2 environments. They argue that the problem lies with the idiomatic tendencies of this type of lexical item.

Consequently, I propose and focus the linguistic inquiry in this instance on nominalisations, Latinate words, phrasal verbs (for lexical items), and sentence length, subordination and passive constructions (for syntactic items) as the variables of investigation.

\section{Methodology}

Concerning methodology, the study combines approaches and research tools in applied linguistics, corpus linguistics and readability studies. Computer-aided linguistic analyses of front-page newspaper stories were carried out to obtain evidence supporting or refuting the assumption that Ghanaian newspapers employ complex language to construct their message. The newspapers used were The Chronicle (Chronicle), Daily Graphic (Graphic), Daily Guide (Guide), and Ghanaian Times (Times). The stories were drawn from the August to November 2008 editions. This data period marked the last quarter of the run-up to a critical general multiparty election in Ghana in 2008.

These four newspapers were the most dominant, credible and influential quality publications in Ghana at the time of the research. In terms of spread, Temin and Smith (2002), Kafewo (2006), Yankson et al. (2010), among others have identified the Daily Graphic, Daily Guide, Ghanaian Times and The Chronicle notionally as the most circulated (in that order) and popular daily newspapers in Ghana. Collectively, the four newspapers comprise about $70 \%$ of the national daily newspapers in circulation in Ghana. Thus, these newspapers were well placed to affect the majority of readers in the country.

Two main specific methods were used within a quantitative-led research design to collect and analyse the data. These are the corpus-based approach (Biber et al. 1998; McEnery et al. 2006) and readability formula tests (see DuBay 2004). These methods provide a framework to computationally investigate the linguistic structure of "the language of a text of a group of speakers/writers" (Biber et al. 1998: 2). 


\section{The corpus-based approach}

The corpus-based approach (and corpus linguistics as a whole) is based on the notion of 'corpus', which according to McEnery and Wilson (2001: 29), is any collection of more than one text. Biber et al. (1998: 4) provide the following essential characteristics of this approach:

- it is empirical, analysing the actual patterns of use in natural texts;

- it utilizes a ... collection of natural texts, known as "corpus," as the basis of analysis;

- it makes extensive use of computers for analysis, using both automatic and interactive techniques;

- it depends on both quantitative and qualitative analytical techniques.

These characteristics enhance the reliability of the analysis and the Wordsmith Tools 6.0 software developed by Mike $\operatorname{Scott}^{1}$ was used. Being computer or software-driven, this method engendered an efficient way of collecting, organising, and enhancing fast, reliable, accurate and diverse manipulations of the data during analysis. In addition to the computational methods designed to yield mainly quantitative analysis, I also applied a manual qualitative-inclined grammatical analysis to support the computational findings. Biber et al. (1998) have suggested the usefulness of applying qualitative analysis to quantitative outputs in corpus-based studies. The linguistic elements specifically targeted and analysed in the corpus included the following in Table 1:

Table 1: The lexical and syntactic units of inquiry

\begin{tabular}{|l|l|}
\hline Lexical & Syntactic \\
\hline$\bullet$ nominalisations & $\bullet$ sentences \\
$\bullet$ Latinate expressions & $\bullet$ clauses \\
$\bullet$ phrasal verbs & $\bullet$ passives forms \\
\hline
\end{tabular}

\section{Readability formula tools}

Readability formulae are mathematical equations whose results provide interpretations for the description of a text from 'very easy' to 'very difficult'. They are meant to help predict or indicate reading ability (in terms of school grade level) required to read and comprehend a particular written text (Redish 2000; DuBay 2004). The formulae are based on research findings that identify vocabulary difficulty (which is

\footnotetext{
${ }^{1}$ See Wordsmith Tools at: http://www.lexically.net/wordsmith/index.html
} 
measured in word familiarity or difficulty, or word length) and sentence structure (measured in sentence length) as two reliable variables in the study of text complexity and difficulty (DuBay 2004; Hulden 2004). These features are equally prominent in measuring or assessing text complexity in (applied) linguistics and legal studies (see McNamara et al., 2010; Lu, 2011). The most frequently cited and used formulae to date are Flesch Reading Ease (1948), Dale-Chall (1946), Gunning Fog Index (1952), The SMOG, and The Bormuth Mean Cloze formulae (DuBay 2004; Anagnostou and Weir 2006). The first three formulae have been the most popular, reliable, tested, and most influential in the field (Du Bay 2004; Hulden 2004). Consequently, these three formula tools were used in the analysis.

\section{Flesch Reading Ease Formula (1948)}

This formula by Rudolph Flesch (1948) depends on two variables: average number of syllables per word (calculated by number of syllables divided by number of words) and average sentence length (i.e. number of words divided by number of sentences). The formula produces a score on a scale of $0-100$. The interpretation is that the higher the score, the easier it is to understand the material. Thus, a score of 30 is very difficult, while 70 is very easy. The equation that generates the Flesch Reading Ease score is as follows:

$$
R E=206.835-(1.015 A S L)-(84.6 A S W)
$$

Where: $\mathrm{RE}=$ reading grade of a reader

ASL $=$ average sentence length

ASW = average number of syllables per word

The prominence and reliability of this formula is suggested by its incorporation and installation in Microsoft Office Word where it is used to check readability levels of texts.

\section{Dale-Chall Formula $(1948,1995)$}

This formula was developed by Edgar Dale and Jeanne Chall in 1948 for adults and children above the $4^{\text {th }}$ grade level. It has been an influential formula and designed to improve on the Flesch Reading Ease Formula. This formula employs a sentencelength variable and a percentage of "hard words." The hard words are those not included in the Dale-Chall (n.d.) list of 763 easy words, $80 \%$ of which are supposed to be known to fourth grade readers (see DuBay 2004). 
The original Dale-Chall Formula was revised by the authors and re-published (Dale and Chall 1995). The new formula is an improved version as it accounted for many readability research findings during the 47 years after the publication of the original formula. The new formula expanded the list of familiar words to 3,000 and was validated against a variety of criteria and correlated highly with other assessment criteria making it one of the most valid of the popular formulae (see DuBay 2004: 52). The score is obtained from the equation (DuBay 2004: 24):

Score $=.1579 * \mathrm{PDW}+.0496 * \mathrm{ASL}+3.6365$

Score $=$ reading grade of a reader who can comprehend a text at $4^{\text {th }}$ grade or below.

PDW $=$ Percentage of Difficult Words (words not on the Dale-Chall word list) $\mathrm{ASL}=$ Average Sentence Length in words.

Concerning interpretation, scores from 8.0 upward imply that the text concerned is difficult and suitable for university students (Dale and Chall 1949).

\section{Gunning Fog Index (1952)}

Robert Gunning's (1952) Fog Index is also a commonly used readability measure developed for adults and based on two variables: average sentence length and the number of words with more than two syllables for each 100 words (Heydari 2012). The formula produces an output that is a grade level score, the equation being:

$$
\text { Grade Level }=.4 \text { (Average Sentence Length }+ \text { hard words })
$$

where, hard words refer to the number of words with more than two syllables. This formula indicates that a score of 13 is the upper limit of an easy text meaning a score above 13 is difficult.

\section{The data}

As indicated at the onset, the Graphic and Times, which were (and still are) stateowned, and the Chronicle and Guide, both privately owned provided the textual data for the study. The corpus-based method helped to systematically collect and organise all the individual news stories reported on the front pages of the selected newspapers over the research period for the overall linguistic analyses. This specialised corpus of front-page news stories represented a language of press reportage of front-page Ghanaian newspaper genre. According to Adolphs (2006: 30), this type of corpus captures "the language of a particular domain rather than the language in general." Data 
were collected from August to November 2008 for the Chronicle, the Graphic, and the Guide. But the four-month data for the Times were so comparatively low that it became necessary to add one more month's data (July) to its (the Times) collection. Thus, care was taken to acquire a near equivalent size in words across the newspapers as much as possible, although there are still some negligible differences in size between the collections. The entire corpus amounted to 896 individual text files or stories with an overall size at 543,698 words. It has to be stated that care was taken to maintain the originality of the stories. Table 2 presents details of the monthly data of the four newspapers.

Table 2: Monthly textual data and size of corpus

\begin{tabular}{|c|c|c|c|c|c|c|c|c|}
\hline & \multicolumn{2}{|c}{ Chronicle } & \multicolumn{2}{c|}{ Graphic } & \multicolumn{2}{c|}{ Guide } & \multicolumn{2}{c|}{ Times } \\
\hline Month & No. of Words No. of Files No. of Words No. of Files No. of Words No. of Files No. of Words No. of Files \\
\hline JULY & & & & & & & 2745 & 57 \\
\hline Aug & $\mathbf{3 9 3 4 8}$ & $\mathbf{5 7}$ & $\mathbf{4 5 8 4 7}$ & $\mathbf{6 8}$ & $\mathbf{3 0 0 4 9}$ & $\mathbf{4 7}$ & $\mathbf{2 6 7 7 5}$ & $\mathbf{5 5}$ \\
\hline Sept & $\mathbf{3 5 3 1 5}$ & $\mathbf{5 7}$ & $\mathbf{3 0 4 5 6}$ & $\mathbf{5 1}$ & $\mathbf{3 2 7 6 7}$ & $\mathbf{4 8}$ & $\mathbf{1 9 9 2 6}$ & $\mathbf{4 4}$ \\
\hline Oct & $\mathbf{3 6 4 4 6}$ & $\mathbf{5 0}$ & $\mathbf{3 6 5 3 4}$ & $\mathbf{6 0}$ & $\mathbf{3 9 5 3 0}$ & $\mathbf{5 4}$ & $\mathbf{2 1 5 5}$ & $\mathbf{5 0}$ \\
\hline Nov & $\mathbf{3 6 0 0 6}$ & $\mathbf{5 1}$ & $\mathbf{2 5 9 4 0}$ & $\mathbf{4 2}$ & $\mathbf{3 7 7 0 1}$ & $\mathbf{5 8}$ & $\mathbf{2 2 0 1 4}$ & $\mathbf{4 7}$ \\
\hline & & & & & & & & \\
\hline TOTALS & $\mathbf{1 4 7 1 1 5}$ & $\mathbf{2 1 5}$ & $\mathbf{1 3 8 7 7 7}$ & $\mathbf{2 2 1}$ & $\mathbf{1 4 0 0 4 7}$ & $\mathbf{2 0 7}$ & $\mathbf{1 1 7 7 5 9}$ & $\mathbf{2 5 3}$ \\
\hline
\end{tabular}

Additionally, a stratified random sampling procedure (Babbie 2005) yielded 20 per cent of text from each newspaper. This produced 160 texts (ten from each month and, therefore, forty from each newspaper). These texts were used for readability text analysis using the three formula tools indicated earlier.

\section{Analyses, findings and discussion}

The corpus analysis concerned general vocabulary and sentence elements. The vocabulary aspect involves the three categories of words that were investigated (nominalisations, Latinate expressions and phrasal verbs). The sentence aspect includes sentence length, clauses and passive form occurrences.

Initial results, as seen in Table 3, show no significant differences in tokens or words and their dynamics across the four newspaper sub-corpora. The results indicate near homogeneity of linguistic features in terms of number of sentences and their averages, and average text or story length. Importantly, the results show that the Graphic, the most widely circulated newspaper in Ghana, had an average sentence and 
word length of 31 and 5 respectively, and about $27 \%$ of its tokens are between 7 and 18-letter words. I have benchmarked word length on seven-letter words upwards because the focus is on words with more than one syllable as potentially complex, and a minimum of seven-letter words provides a reliable indicator of such words. For instance, a six-letter word such as months is one syllable. This finding about the near homogeneity of the linguistic features analysed seems to suggest that the newspapers share similar linguistic characteristics and targeted readership.

Table 3: Statistical details of the corpus data

\begin{tabular}{|c|c|c|c|c|}
\hline ITEMS & CHRONICLE & GRAPHIC & GUIDE & TIMES \\
\hline Tokens or Running Words & 148350 & 140761 & 141338 & 119413 \\
\hline Tokens Used for wordlist & 147115 & 138777 & 140047 & 117759 \\
\hline Types (distinct Words) & 11279 & 10945 & 11450 & 10702 \\
\hline Type/token Ratio (TTR) & 8 & 8 & 8 & 9 \\
\hline Standardised TTR & 40.33 & 40.06 & 43.06 & 43.38 \\
\hline Mean Word Length & 5 & 5 & 5 & 5 \\
\hline Total No. of Sentences & 4585 & 4403 & 4661 & 4108 \\
\hline Mean Sentence Length & 32 & 32 & 30 & 29 \\
\hline Std. Dev., Av. Sent. Length & 15.41 & 13.36 & 13.53 & 12.68 \\
\hline No. of texts & 215 & 221 & 207 & 253 \\
\hline Mean Length of Text (Words & 684 & 628 & 677 & 465 \\
\hline 7-letter Words and above & 37699 & 37407 & 34674 & 31069 \\
\hline
\end{tabular}

The general information presented above provides initial cues about the nature of the language of the corpus. The next section begins a detailed discussion toward an informed description of the language.

\section{Lexical complexity}

Results concerning word frequency and length provide an initial indicator towards an assessment of the language of the corpus. The statistical analysis involving the wordlist indicates that $64 \%$ of the lexical items of the corpus occurred four times or less over the four-month data period. This implies that the corpus exhibits very low frequency of such words, suggesting that the words may be unfamiliar. This measure has been an important and long-standing measure of readability. Lexical items may have low occurrence in a text, especially in short texts (Sinclair 1991; Adolphs 2006), but scholars have argued that less frequent words are less common to most readers and 
since such words are less frequently encountered, they draw longer eye fixation time and thus pose comprehension challenges (Just and Carpenter 1980, 1992; McNamara et al. 2010). The importance of this finding is emphasised by the fact that the majority of these low frequency words are Latinate and/or nominalised expressions, which have characteristics that make texts in which they occur complex.

Additionally, the analysis indicates that the average word length of the corpus is 5 letters and that $26 \%$ of the words in the corpus $(\mathrm{N}=543698)$ are 7 to 18 letters as shown in Figure 1. These findings imply that over a quarter of the words in this study's corpus were long words, which could exert a relative burden on mental processing during reading. Examples of some of the words are captured below:

\section{Letter word}

8

9

10

11

12

13

14

15

16

17

18
Examples

comment, tension, faction impunity, capacity, dynamism augmented, dimension, rationale precaution, commitment, sentiments devastation, tranquillity, impediments dispensation, intervention, surveillance documentation, collaboration, eventualities discrimination, accountability, disenchantment competitiveness, professionalism, familiarisation decentralization, inter-ministerial, intercontinental maladministration, industrialisation, misrepresentation telecommunications, characteristically

A normalised ${ }^{2}$ comparison of the frequency of long words (7 to 18-letter words) with the British National Corpus (BNC) ${ }^{3}$ indicated that the 140,849 words of our corpus map to $25,351,583$ words of the BNC's $23 \%(22,349,769)$ proportion of such words. ${ }^{4}$ This means that there could be more of such long words in our corpus than in the about 100 million-word BNC. Although the BNC contains 10\% spoken language, the $90 \%$ written component contains technical and academic texts that may contain long words.

${ }^{2}$ According to Biber et al. (1998: 263), "[n]ormalization is a way to adjust raw frequency counts from texts of different lengths so that they can be compared accurately."

${ }^{3}$ The BNC is a 100 million balanced and representative corpus of British English. It is made up of $90 \%$ written and $10 \%$ spoken texts and has been used for many corpus-related studies (Davies, 2009).

${ }^{4}$ Scott, M. 2012. BNC Wordlist. Available from: http://www.lexically.net/downloads/version4/downloading\%20BNC.htm. 
This possibility makes the results of this study significant, especially as the corpus is a newspaper genre and not a technical publication.

Figure 1: Percentage of long words (7 to 18 letters) in the corpus

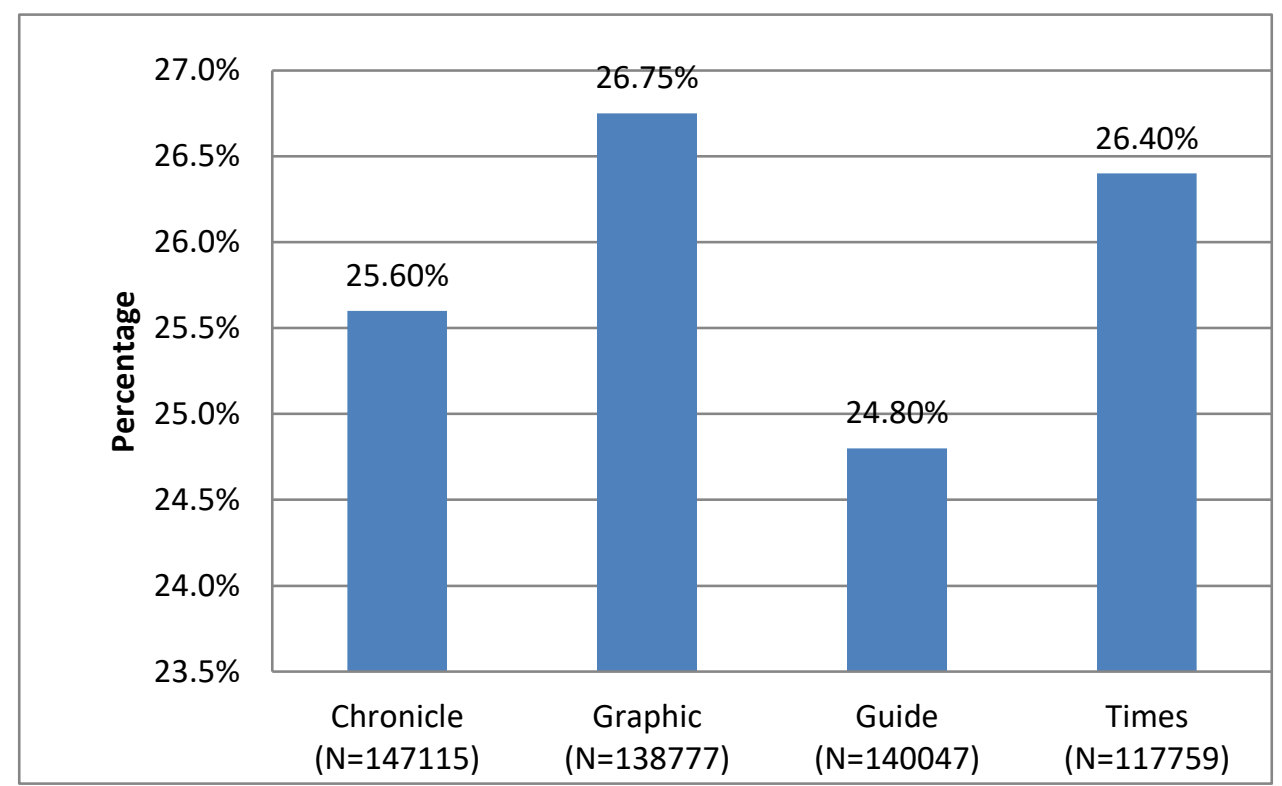

\section{The Lexical items}

From the general description of the corpus, attention is now focused on the specific lexical items under investigation. Table 4 presents overall results of the three categories of lexical items investigated in terms of proportions in each newspaper. The results indicate that Latinate expressions consistently occurred the most in the subcorpora at an average of almost $10 \%$. A detailed discussion of how these findings individually and collectively influence the text is presented shortly. 
Table 4: General occurrence of the lexical items under study

LEXICAL ITEM

$\begin{array}{lrrrrr}\text { Nominalisations } & 7236 & 7250 & 5780 & 6142 & \mathbf{2 6 4 0 8} \\ \text { Latinate Expr. } & 13491 & 13278 & 10711 & 11283 & \mathbf{4 8 7 6 3} \\ \text { Phrasal Verbs } & 1443 & 1062 & 1056 & 865 & \mathbf{4 4 2 6}\end{array}$

Figure 2 presents a clearer picture in percentages of the various proportions of the lexical items. In the next subsections, I present a detailed discussion of the analytical procedures and results of the individual elements.

Figure 2: Percentage of lexical items in the corpus

\section{Nominalisations}

The results indicate that of the 26,408 nominalisations in the corpus, those

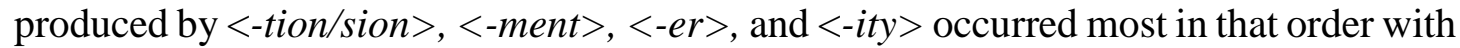
$<-$ tion/sion> constituting between $35 \%$ and $43 \%$ across the sub-corpora see (Figure 3).

Figure 3: Four highest occurring nominalisations in the corpus

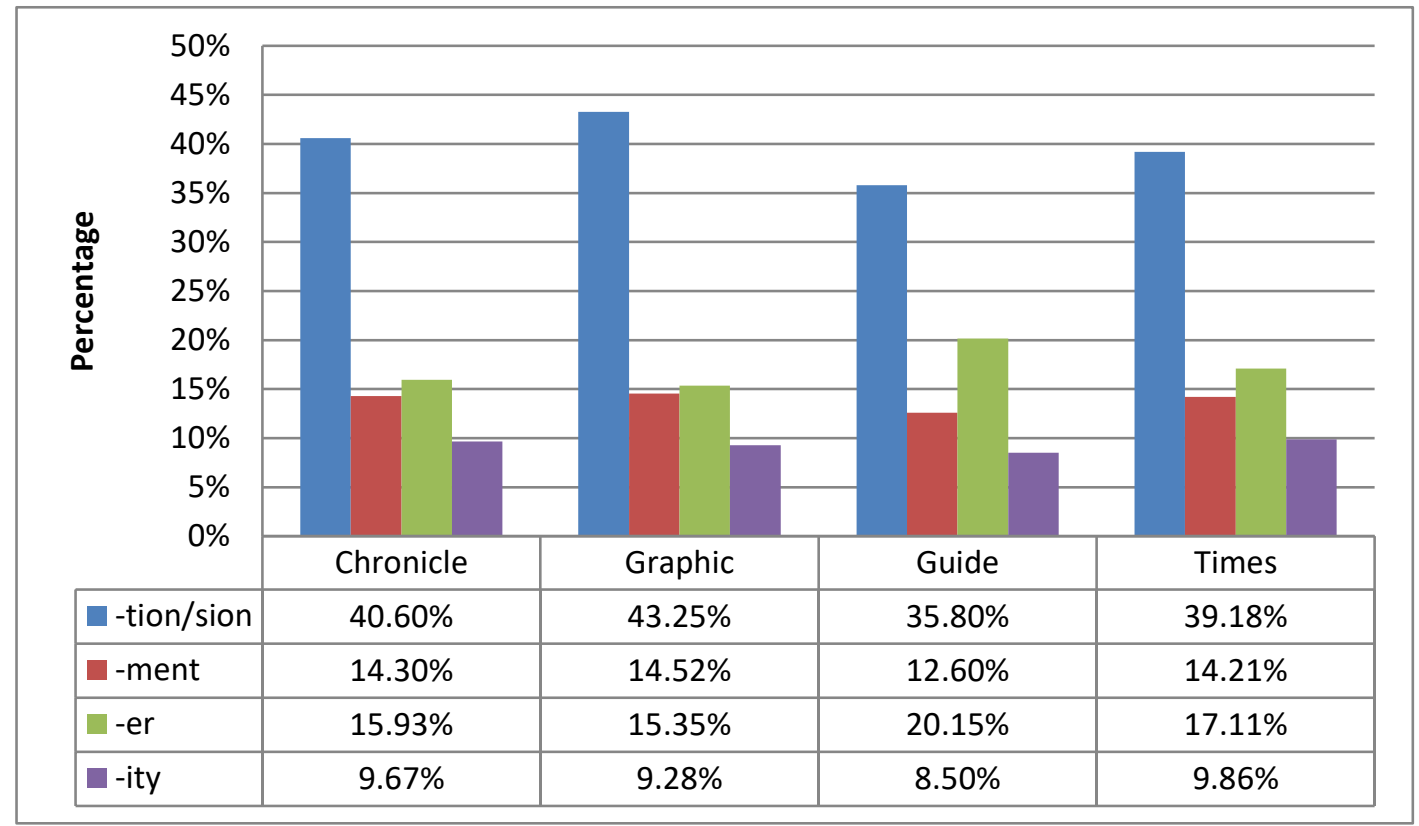




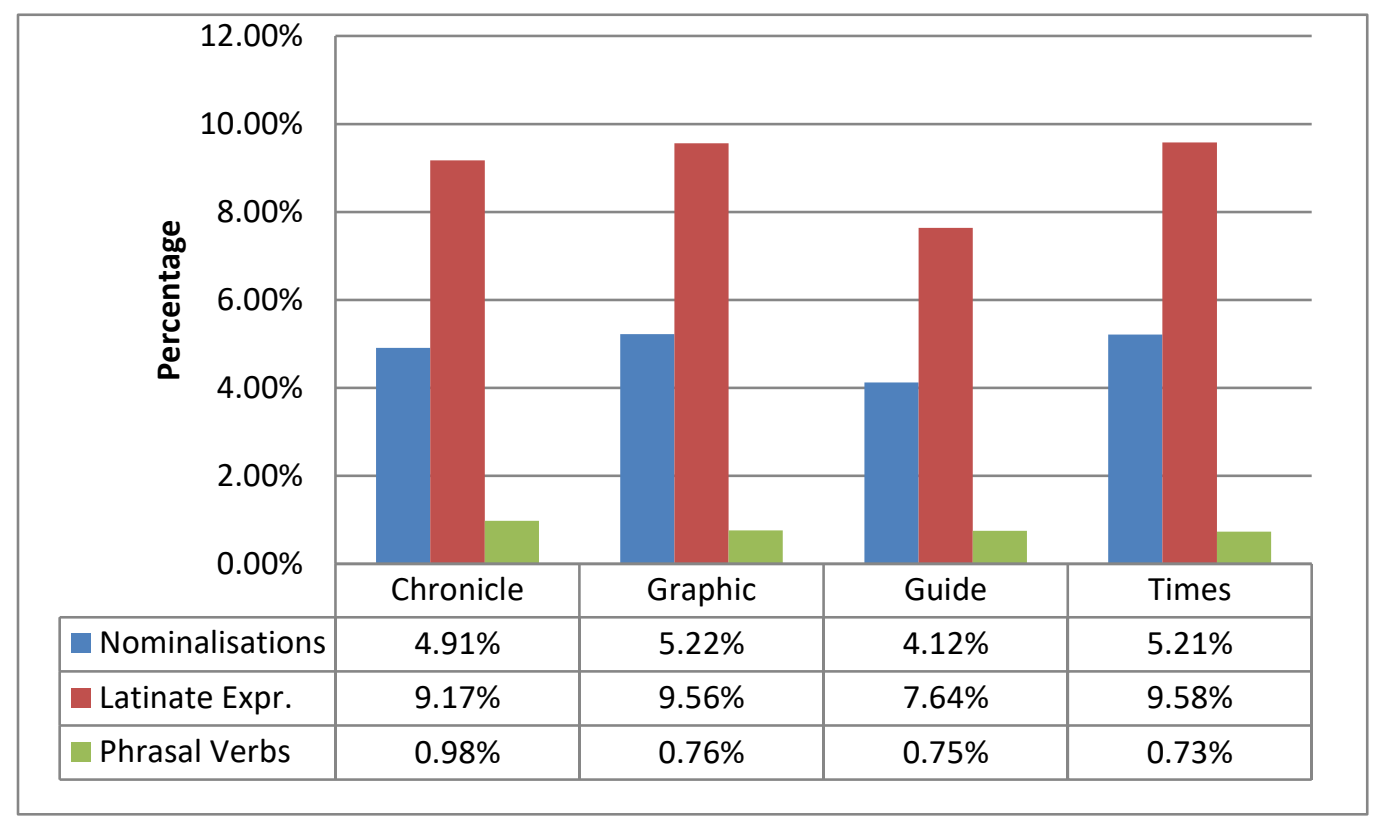

These types of nominalisations and the proportion of their occurrences across the newspapers ${ }^{5}$ are in line with trends in academic writing (Biber et al. 1998; Biber et al. 1999). Using nominalisations formed from <-tion/sion, -ment, -ity and -ness> across three registers (academic prose, fiction and speech), Biber et al. 1998 discovered that nominalisations occurred most in academic prose and explained that the abstract quality of the nominalised words suits the nature of academic writing. Therefore, the occurrences of these nominalisations in this current corpus suggest that the language of the newspapers is similar, in respect of nominalisations, to that of academic prose.

In terms of how nominalisations contribute to text complexity and difficulty, Biber et al. (1998: 61), explain that the nominalisation process converts actions, processes and descriptive qualities into abstract objects that are separate from human participants. The writers use the nominalised word movement in "if movement has occurred recently, the effect on topography drainage patterns, vegetation ... recognised" to explain that movement, as a process, has been nominalised (as the subject in the sentence) implying that the text now discusses the "generalized action of

${ }^{5}$ The exception is -er, which most studies appear to ignore but which was productive in this study. Similarly, the suffix -ness did not yield significant occurrences because it converts an adjective into a noun to express personal feelings and qualities, which newspapers do not often report. 
moving, rather than a particular person moving." The example below from our corpus illustrates the argument further.

Such support, he said, should manifest itself in the timely release of resources for critical programmes in the shared plans, since delays in the implementation of programmes had led to frustrations and tended to cause political disenchantment, which has rendered some governments in democratic countries vulnerable (Graphic Sept. 52008 story 2).

From the above, "implementation" and "frustrations" are -tion/sion nominalisations from the verbs implement and frustrate. Their use has converted the action and state represented in them respectively to abstract objects in a way that eliminates the human agent. In other words, it is not clear who is 'implementing' or 'feeling frustrated.'

Critical discourse analysts such as Fowler (1991) and others have used systemic functional grammar to demonstrate how nominalisation is used, especially in the press, as a metaphor to deliberately conceal issues or mislead readers (Fowler 1991, Stenvall 2011). This conclusion is because nominalised words are abstract and vague as explained earlier. However, it is difficult to sustain the argument that any time a nominalisation occurs in the press, it implies a deliberate act of concealment. The use of nominalisations could also be a matter of the writer's writing style and may not always occur intentionally to confuse or hide something (Stenvall 2011). Nevertheless, there seems to be consensus that the occurrence of many nominalisations in a text, whether intentionally to hide an idea or not, has the potential of making the language complex and difficult, especially due to their abstract nature.

\section{Latinate expressions}

As indicated earlier, about $10 \%$ of the lexical items in the corpus are Latinate expressions. Four of the results that occurred most were produced by the affixes < $\mathrm{co}$ \rangle,$\langle p r-\rangle$, $\langle i n-\rangle$, and $\langle d e-\rangle$ across the newspapers as presented in Figure 4. The results indicate that the majority of Latinate words in Ghanaian newspaper front-page stories are prefixed by $\langle\mathrm{co}-\rangle$, which occurred between $25 \%$ and $26 \%$ among the Latinate words identified across the various newspapers. Instances of such words include collaborate, commemorate, commitment, conjecture, consent, corroborate, counsel, covetous, among others. 
Figure 4: Four highest occurring affixes and their Latinate items

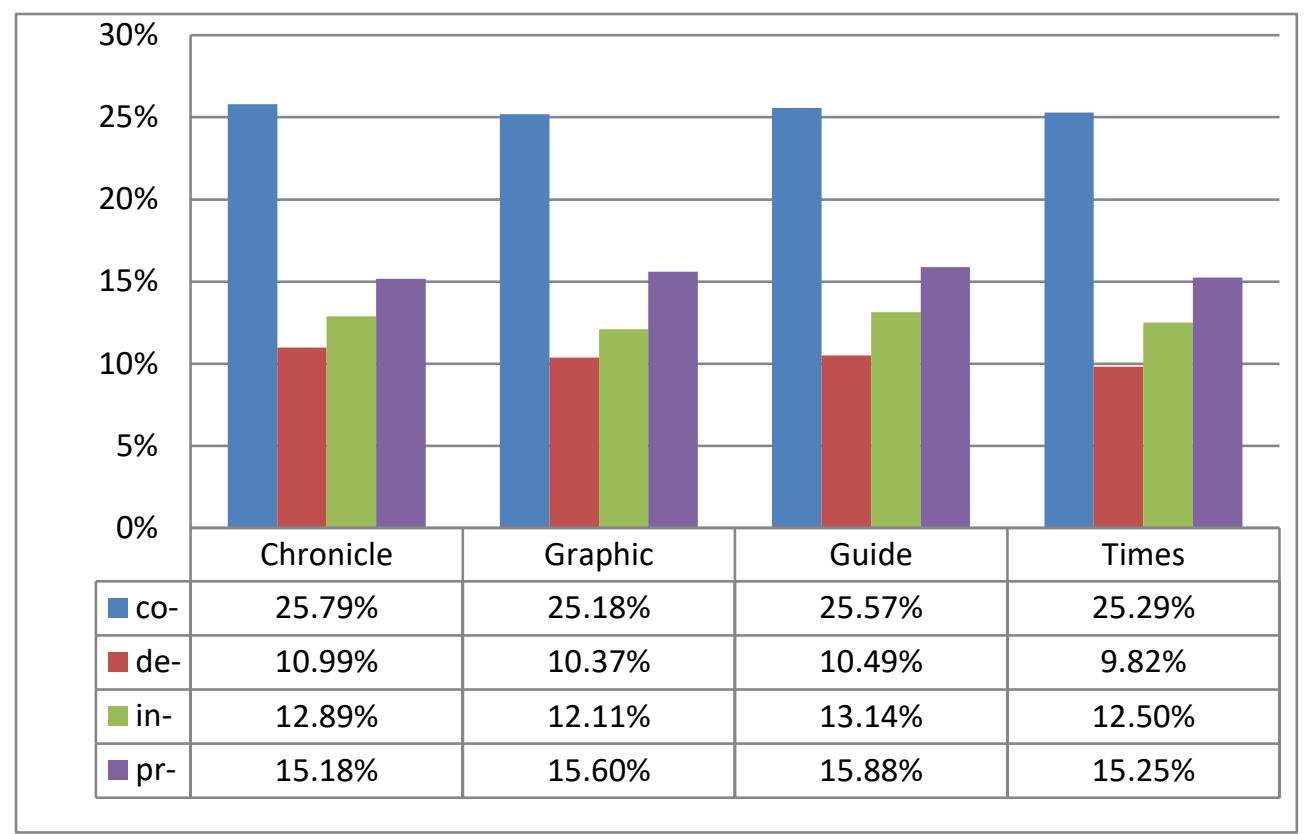

In addition to the above systematically generated output, the following are some instances of Latinate vocabulary in the corpus, which did not fall neatly into any of the above groups:

aptitude, legacy, elated, vicinity, attitude, sanction, faction, volition, jurisdiction, rationale, authority, dimension, legacy, envisage, legal, monument, assessment, criteria, admonish, metropolitan, logistics, immigration, manifesto, remand, critical, implementation, motion

The findings and analysis suggest a widespread use of Latinate words across the newspapers most of which are long and polysyllabic. It is clear from the results that the language of the newspapers compares with academic or legal writing. Concerning complexity, the usually long or polysyllabic and abstract nature of Latinate expressions makes the language of the text in which they occur formal and specialised, as in academic and legal texts (Russell 2001). I argue that a text with such a characteristic is suitable for a specialised, and not general, audience. Thus, the over $\mathbf{1 0 \%}$ of such lexis in this corpus has a significant implication for the complexity of the language. The example below qualitatively illustrates this point. 
The court said it took into consideration the prevalence of armed robbery in the country, the overwhelming evidence adduced against the convicts by the prosecution, the character and antecedents of the convicts, among others, before imposing the sentence (Daily Graphic September 17 Story 2).

The extract, taken from one of the newspapers under discussion, is part of a report on a court case, and it contains Latinate words such as consideration, prevalence, adduced, prosecution, character, antecedents, and sentence. The use of legalese such as prosecution and sentence occur alongside other Latinate words to make the extract formal and technical. These words are usually associated with the kind of formal writing found in technical reports, academic and scientific documents that may not be for public consumption.

\section{Phrasal verbs (PVs)}

The analysis yielded PVs in the corpus including work out, put up with, spew out, turned up, speed up, setting up, get along with, fashion out, among others. The quantity of PVs in the corpus is 4,426 , which comes to less than $1 \%$ of tokens in the corpus. The relatively few PVs across the sub-corpora seem to confirm studies that they are rare features in second language (L2) writing (Dagut and Laufer 1985; Laufer and Eliasson 1993). This notwithstanding, a normalised comparison with PVs in the Corpus of Contemporary American English's (COCA) 676 million-word newspaper component (4,720 per million words) (Davies 2009: 183) seems to suggest that the occurrence in this study's corpus is considerable and hence significant. The normalised results (with 1000 as the denominator) indicate that the occurrence of PVs in our corpus (8.14) is almost twice as much as what occurs in the COCA (4.72).

The results indicate that the PVs used in Ghanaian front-page stories reflect three types of PVs. Spew out and sped off, meaning say unpalatable things and move away in haste respectively, belong to the literal type. Stay over (sleep overnight at a place) and speed up (increase the pace) are instances of completive PVs, while turn up (arrive), set up (establish) are figurative. Any reader who does not know the collective meaning could miss the import of these lexical items, and this may affect the overall understanding of the sentence in which the lexis appeared as well as the language of the text as a whole.

${ }^{6} \mathrm{COCA}$ refers to the Corpus of contemporary American English that keeps growing because new texts and words are added each year. Thus, it is one of the most current useful corpora available. The corpus is over 450 million words. By 2008, it was over 350 million (Davies, 2009). In terms of research application, the COCA is comparable to the BNC. 
Concerning the complex aspect of PVs, Sinclair (1991: 68) notes that PVs have been of interest to language teaching since they offer "exquisite problems to learners." Particularly relevant has been the finding suggesting that the use of PVs is generally uncommon among L2 users mainly because the PV structure does not exist in the users' L1 (Dagut and Laufer 1985; Liao and Fukuya 2002). The consequence is the hypothesis that L2 users avoid PVs and therefore find them difficult to understand (Dagut and Laufer 1985; Liao and Fukuya 2002).

\section{Overall significance of findings concerning lexical items}

The significance of the results involving word length and these three categories of lexical elements relative to text complexity lies in their collective occurrences in the corpus. The proportion of such words, particularly nominalisations and Latinate, has significant text complexity implications for the language of the corpus as a whole. Research has established that grammatical or function words such as on, in, upon, $a$, the, etc., constitute about half of the tokens of any text or corpus (Nation 2001; Adolphs 2006). Yet such words do not carry content or information. This means that the lexical items investigated form part of the remaining words that carry information in the corpus. Thus, since almost $\mathbf{1 0 \%}$ of the information-laden words of the corpus are Latinate and potentially unfamiliar, there is a strong case for the complexity of the language. as the following examples, which easily popped up in the analysis suggest:

motion, commended, challenges, constituencies, electioneering, entourage, investigations, aspirants, cautioned, perpetrators, assurance, reiterate, municipal, metropolis, multi, millennium, dialysis, transparent, adjudication incumbent, indigenes, circumspection, dispensation, entrenchment, mandatory, prosecution, intimated, inauguration, interact, communiqué, characterised, candidature, interlocutory, etc.

\section{Syntactic complexity}

Studies in syntactic complexity have often relied on the relationships between sentence length, clauses and other internal linguistic units of a sentence using the number of occurrences and averages as measures (Norris and Ortega 2009; Lu 2011). In this study, four specific syntactic variables were used: sentence length, types of sentence, clause embedding and passive constructions. These are first discussed individually and then their collective impact on the language of the corpus is summed up. 


\section{Sentence length, clause embedding, and sentence types}

I discuss here the above three variables because of their close association. Concerning sentence length, the corpus analysis indicates that the average sentence length is 31 words with the Chronicle and the Graphic scoring 32. This finding is far above existing journalistic standards or research recommendations. The news reportage component of the corpus that was used to produce Biber et al.'s (1999) Longman Grammar of Spoken and Written English has a mean sentence length of 20 words. Most researchers and experts (in readability and plain English studies) agree that written information for public communication is best presented in sentences of between 15 to 25 words (Flesch 1949; Russell 2001; DuBay 2004). For example, Essential Reporting: NCTJ Guide for Trainee Journalists (Smith 2007) advises journalists to use an average sentence length of 20 words.

The occurrence of relatively long sentences in the corpus has implications for readability, no matter the accompanying number of short sentences. Although the standard deviation of the average sentence length was 13.75, which indicates relatively dispersed sentence lengths, the study showed that the corpus contains many long sentences. For instance, a sentence such as the one below from the Guide is so long (75 words) that at the end, the sentence shifts focus from a comparison of the strengths of Mahama and Bawumia ${ }^{7}$ to introduce another issue on some voters' belief.

While Mr. Mahama is perceived to be more expressive with a richer experience on the political soapbox, Dr. Bawumia's understanding of Ghana's current economic challenges and his direct involvement in stabilizing the country's financial sector has earned him the reverence of the business community and that class of voters who do not vote on party lines but on the belief that the country needs a leader who can transform the economy into a first-class one (Guide August 21, story 1).

Thus, by the time the reader gets to the issue of the belief, he/she could have forgotten how the sentence began. The argument, in relative terms, is that the longer a sentence the more clauses it may contain and therefore the more complex it becomes. As I discuss further below, long sentences usually contain clauses with various linking processes that reveal other patterns of complexity.

\footnotetext{
${ }^{7}$ Mr. John Mahama and Dr. Mahamadu Bawumia were the running mates of the presidential candidates of the National Democratic Congress (NDC) and the New Patriotic Party (NPP), respectively, during the national elections in Ghana in 2008. These two parties were the frontrunners of that election.
} 
The sentences of the corpus display other internal structure characteristics that point to complexity. Table 5 indicates that each sentence of the corpus is a complex sentence.

Table 5: Syntactic profile of the corpus

\begin{tabular}{|l|r|r|r|r|}
\hline & $\begin{array}{r}\text { Total } \\
\text { No. of Clauses }\end{array}$ & $\begin{array}{r}\text { \% of } \\
\text { Sub- clauses }\end{array}$ & $\begin{array}{r}\text { \% of } \\
\text { Relative } \\
\text { Clauses }\end{array}$ & $\begin{array}{r}\text { \% of } \\
\text { Passive Forms }\end{array}$ \\
\hline Chronicle & 13030 & 51.81 & 12.29 & 18.19 \\
\hline Graphic & 11674 & 53.79 & 11.89 & 13.20 \\
\hline Guide & 12717 & 51.45 & 12.55 & 13.47 \\
\hline Times & 11279 & 51.19 & 12.04 & 14.00 \\
\hline
\end{tabular}

The complex sentences are further complicated by the way the clauses relate to one another. Studies on clause grammar argue that the clause serves as a unit of thought (Biber 1999), so it is reasonable to assume that a complex sentence contains more than one idea. In relative terms, the processes involved in creating a complex sentence (that is, subordination) are grammatically intricate, and may relate to efforts needed to decode such sentences (Just and Carpenter 1992; Russell 2001). It is argued further that the ideas in a complex sentence interact in an embedded or firmer relationship (depending on the number of clauses) and this and other linguistic (and non-linguistic) factors may combine to make that sentence potentially difficult to deal with semantically, as explained further in the example below:

a. Mr. Aggrey-Mensah said when Telekom Malaysia's agreement was abrogated, it was the poor GT, which did not benefit from the sale that was made to pay the \$52 2 million as settlement fee (Graphic 2 August 2008).

Example (a) above has five clauses with a more intricate structure. The various clauses, each presenting an idea, are as follows:

- Mr. Aggrey-Mensah said (it);

- (that) it was the poor GT (which did not benefit from the sale);

- When Telekom Malaysia's agreement was abrogated;

- Which did not benefit from the sale; and 
- That was made to pay the $\$ 522$ million as settlement fee

The independent or main clause is Mr Aggrey-Mensah said (it), where it refers to it was the poor GT, which did not benefit from the sale. This clause is itself a complex one because it has an implied or obligatory relative clause (in bold italics) that describes the poor GT. The four conjunctions in bold, that is, omitted that, when, which and that, signal the dependent clauses in that order. The first dependent clause is the direct object of said and so it is nominal. The second, indicated by when, is adverbial adding time to the idea it contributes to the sentence. The other two dependent clauses are relative or adjectival, describing the poor $G T$ and the sale respectively. If a reader fails to connect the conjunctions or relative pronouns, that is, which and that, to their correct noun as explained above, meaning could be lost. Additionally, if all these clause structures are not properly related and understood in the context explained above, there could be meaning challenges.

\section{Passive forms}

The study acknowledges three types of passives as illustrated below:

- He was released by the prison authorities. (full or long: BE + Past Participle)

- The evidence given by the witness solved the case. (Partial: minus BE)

- The evidence by a witness solved the case. (fully ellipted: but implied)

The results indicate about $15 \%$ long passives in the corpus (see Table 5). The focus on passive forms was based on the notion that they make sentences formal, impersonal and 'weighty' (Biber et al. ibid.). The passive voice has been identified in discussions concerning plain English and applied linguistics as a key contributor to text complexity and reading difficulty (Loughran and McDonald 2009; Amdur et al. 2010; Ferreira et al. 2002), although few of these studies have discussed specifically how the construction interferes with meaning making. There is, therefore, the need for more research on this. Amdur et al. (2010) recommend that there should not be too many passives in articles published in medical journals since they make reading and understanding difficult. This suggests, importantly, that passive constructions could affect reading and understanding, especially in public documents such as newspapers. Ferreira et al. (2002) also examined the issue of misinterpretation of passive sentences and discovered that while their participants identified the improbability of the statement, The man bit the dog, about $20 \%$ of the participants found the statement, The dog was bitten by the man, plausible. The writers, consequently, argued that readers 
sometimes are unable to apply the meaning implication in the passive verb form. The example below should help to further clarify the issue.

b. Led in evidence by a State Attorney, T. Amponsah, the first prosecution witness, Musah Hassan, told the court that he is a businessman operating at the Central Business District of Accra (Guide August 27 2008).

In the example, (was) Led is the passive verb, while a state attorney, T. Amponsah, is the agent. The act of leading 'affects' Musah Hassan, but the passive form seems to portray the state attorney as the one who was led in evidence. The sentence was particularly made confusing by the inversion in which the subject of the passive verb (Musah Hassan) is removed from the verb. Thus, it would seem as if Musah Hassan is not affected by the action of state attorney, and this is a possible source of complexity.

\section{Readability formula tests}

The results for the three formula tools indicate a high level of consistent correlations in terms of the relative ease or difficulty of the texts even across the individual text scores. As indicated in Figure 6, the overall average scores obtained across the four newspapers for Fog were between 16.32 and 18.13. Scores for Flesch were between 41.37 and 34.73 and Dale, between 8.59 and 8.86. The standard deviation for most of the scores was below 0 , showing how clustered the results were over the period. By interpretation, the scores indicated largely that the language of the four newspapers is difficult and suitable for college/university level readers. 
Figure 6: Results of readability tests

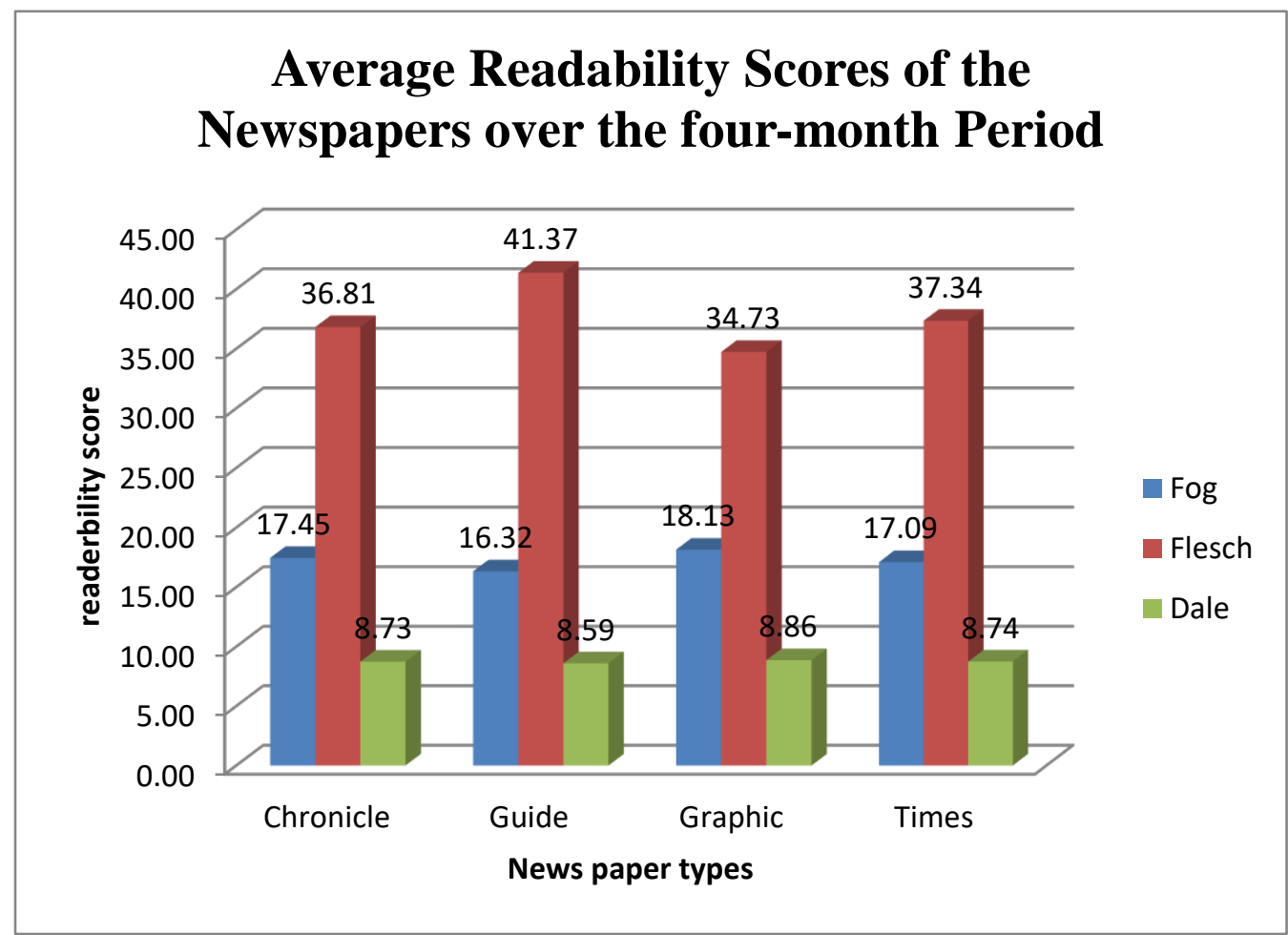

Key to the Interpretation of the above Scores (from DuBay 2004: 25):

- Fog Index: 5 is readable; 10 is hard; 13 is difficult; and 20 is very difficult. (Note that, college or university level has a score of 10 or less)

- Flesch Reading Ease: the higher the score the easier to read; $70-100$ indicates from easy to very easy to read; $0-30$, very difficult to read (post university or college graduate); $30-50$, difficult to read (university/college graduate); 60-70, standard.

- New Dale-Chall: 4.9 and below, for grade 4 and below; 5.0 - 6.9, for grades $5-6 ; 7.0-7.9$, for grades $9-10 ; 8.0-8.9$, for grades $11-12$; $9.0-9.9$, for grades $13-15$ (college level); 10 and above for grade 16 and up. 
The monthly averages for each formula reflected almost the same pattern. Thus, I narrow the analysis to results produced by Fog. The Fog formula measures difficulty based on word syllable count (word length) and sentence length, which suits the major orientation and argument of this study regarding the sources of newspaper language complexity. For the monthly results, the August scores for Fog for the four newspapers were between 16.00 and 18.46 where the Guide had the least difficult score and Graphic the most difficult score. For September, the range was 16.62 and 18.19 with the Guide and the Chronicle having the least and most difficult scores, respectively. October averages for Fog were between 16.38 and 18.37 and the least difficult was the Times while the Graphic was the most difficult. Similarly, the scores for November ranged between 16.03 and 18.54 with the Guide and the Graphic having the least and most difficult scores, respectively. The same pattern is reflected in the scores of the other readability tools. The monthly results over the period indicate the consistency of the writing style of the newspapers within a score range interpreted as difficult, and this strengthens the assumption of the study that Ghanaian newspapers employ a similar writing style or language.

Concerning interpretation, the individual text scores of the three formulae indicate clusters within the same interpretation ranges. The majority of scores for Fog were between 15 and 19.9, when the danger line for readability is 13 (Gunning 1952; Heydary 2012). In fact, according to the Fog formula, news is expected to read at a score of 10 (see DuBay 2004:25). The interpretation for all the tools is that the Ghanaian newspapers read at the difficult level, and this indicates that the material is largely suitable for university or tertiary level readers. In terms of percentages, results of texts for each newspaper that scored difficult and above are presented in Figure 7. A remarkably high $80 \%-93 \%$ of the 40 news stories of each of the newspapers are difficult and readable largely by university level readers. 
Figure 7: Readability test results showing percentage of difficult news texts

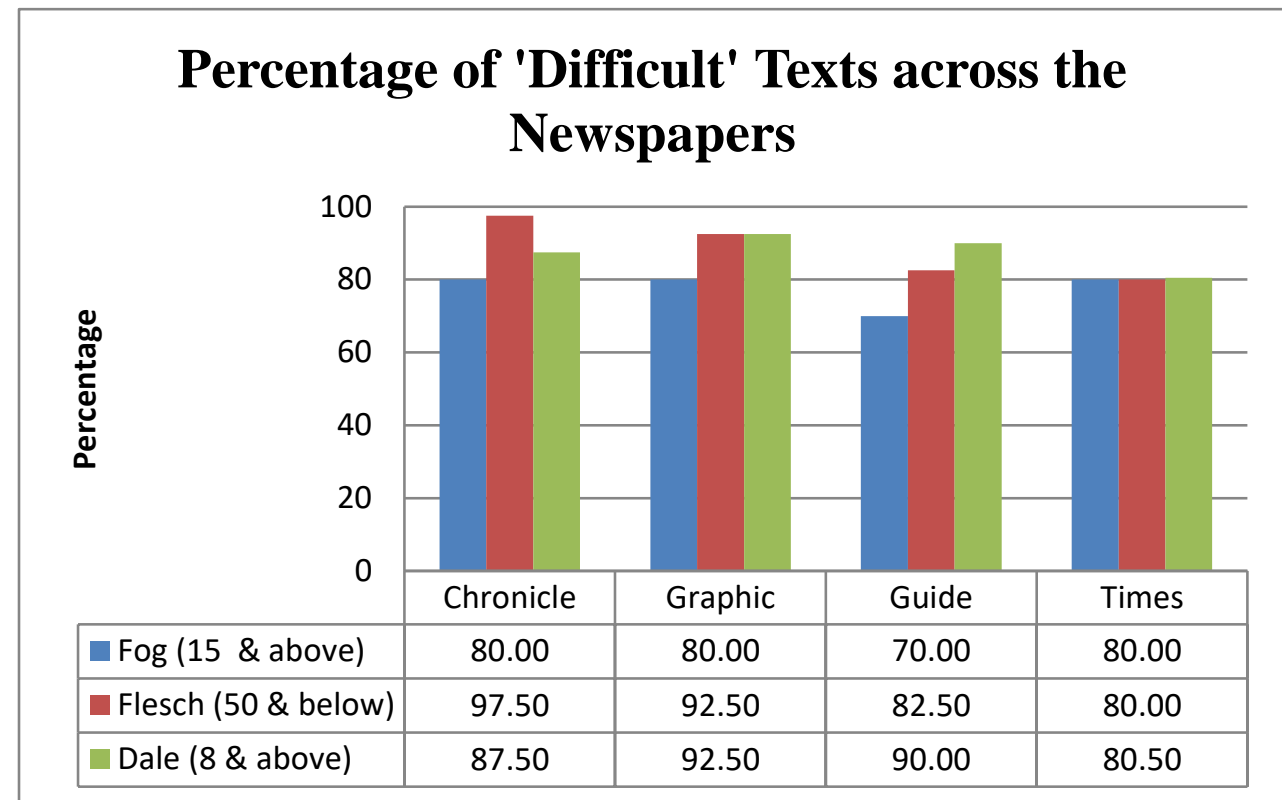

Results of the corpus linguistics analysis clearly correlate strongly with findings of the readability formula tools. The strong representation of long words and sentences in the corpus seem to be reflected in the readability scores. Therefore, results of these two perspectives triangulate to suggest that the complexity level of the newspapers' language could largely challenge readability.

\section{Further discussion: Ghanaian newspapers, text complexity and comprehensibility}

The analyses, results and discussion above provide adequate evidence that the language of the corpus is structurally highly complex. This is based on the proportions and blend of the linguistic features investigated and other tendencies generated by them. Vocabulary provided the most reliable evidence about the complexity of the language. The results indicated that the newspapers contain many long words, nominalisations, Latinate expressions and phrasal verbs in proportions that individually and collectively predispose the language to complexity.

The relationship between syntax and text complexity was established through sentence length, complex sentence and clauses, and passive forms. The study found on average that the newspapers employ long sentences while scholars and media industry experts have suggested the use of short sentences of between 15 and 25 as the readable length. The analysis also shows that each sentence of the corpus is complex with intricate clause embedding. Going by the notion that a clause is a unit of thought, the 
implication is that each sentence of the corpus contains a number of ideas. Thus, when these ideas occur in intricate sentence structures as demonstrated manually in the analysis, readers' memory and recall are challenged.

The notional complexity of the text was corroborated by results of the readability formula analysis, which indicate that on average, $\mathbf{8 5 \%}$ of the texts of the various newspapers were difficult and readable by readers with university educational attainment. Although readability formulae have been criticised, especially in their use to guide the writing and revision of documents (Redish and Selzer 1985; Redish 2000), they remain reliable tools in determining levels of language complexity (DuBay 2004). Their relevance in this instance is the fact that this study was not meant to revise or guide the writing of newspaper stories but just to indicate readability levels.

From the near similarity of the results across the four newspapers as seen from the different analyses, it is reasonable to apply a homogeneous description to the language of the front-page stories of the national daily newspapers in Ghana and describe it collectively as complex. The findings, therefore, suggest strongly that the language of Ghanaian newspapers could hinder the readability and comprehensibility of the front-page stories, particularly for many pre-university readers.

This discussion so far raises questions about the target of the newspapers, newspaper-based information flow, information access and knowledge acquisition. These issues are best understood within the framework of the educational culture of the country. The point has been made that formal English in which Ghanaian newspapers construct news reports is acquired in school. Ghana's education structure covers basic (Primary and Junior High), secondary (Senior High) and Higher Education (polytechnic, university, etc.) levels, and the higher one goes up this ladder, the more one is able to use and understand a relatively complex form of the language. That is why the complex language of the newspapers as discovered in this study could largely suit tertiary level readers. The fact that only a few educated Ghanaians access Higher Education (about 4\%) 8 leaving the overwhelming majority of such people at basic and secondary levels implies that many readers or potential readers of newspapers could find it difficult reading and understanding news stories on account of the language. It could even be possible that some tertiary level readers also find it hard to read and understand such language.

Education in Ghana has faced challenges since the post-independence period in line with the country's developing status. These challenges provide some reasons for the relatively low education quality, standards, abilities and attainments in the country (Awedoba 2001; Owu-Ewie 2006, 2014; Akyeampong et al. 2007; Ampiah 2010).

${ }^{8}$ See Ghana Statistical Service (2013). 2010 population \& housing Census. From: http://www.statsghana.gov.gh/docfiles/2010phc/National_Analytical_Report.pdf 
Consequently, it is not surprising that issues concerning competence in English are often topical in Ghana. Owu-Ewie (2006) and Fosu (2009), for example, express concern that many students finish school but lack competence in English contrary to society's expectations. Indeed, examination results at all levels of the country's educational structure have shown over the years that students perform poorly in English, far more than they do in other subjects (from Chief Examiner's reports, West African Examinations Council). Relating the discussion to the press, this state of affairs raises critical questions about the relationship between education, language of newspapers, and readers' ability to read the newspapers.

The above scenario has implications for information flow and readers' direct access to socio-political information and knowledge. Specifically, the argument is that many educated Ghanaians, alongside the many who cannot read and write, could be alienated from directly accessing the news, thereby creating gaps in newspaper-based knowledge in the society with dire political consequences (Kleinnijenhuis 1991; Eveland Jr. and Scheufele 2000). Thus, while Nisbet (2008: 474) has discovered that education is a leading pointer to communication gaps in some transitional democratic societies, this current study has discovered that language challenges could be an additional education-related cause of the gaps in Ghana. The implication is that a few elites may continue to have dominion over political information and knowledge, which grants them power to represent their version of reality and interests as the society's.

The above suggestion raises critical questions about readership. As Douglas (2009:50) observes, newspapers survive on the active patronage of their "core loyal readership", that is, the regular buyers of newspapers. Logically, this implies that newspapers also adopt political and ideological viewpoints, as well as language, that sit well with their readers. Thus, newspapers consciously construct their "ideal or implied" readers by writing with the readers in mind and seeking their comfort (Fowler, 1991:232).

Yet, while the Ghanaian press has been known to champion different ideologies and political positions, readership has not exactly reflected segmentation or the 'ideal or implied reader' around newspapers and their positions. For instance, about $80 \%$ of Ghanaian readers consume the Graphic, which is state-funded and perceived to be progovernment, although it is clear from national election results that many of the readers might not be sympathetic to the political ideology of the government of the day. The same situation applies to many of the national newspapers. Thus, it is not surprising, considering the findings of this study, that the national newspapers target every possible reader. If so, it is expected that the readers of each Ghanaian newspaper are likely to be a heterogeneous collection with different characteristics, especially educationally. Consequently, I argue that one of the ways in which Ghanaian newspapers can construct their readers and ensure their comfort is in the use of language, in addition to political 
and ideological positioning. It is hence reasonable to hypothesise that newspapers will employ language that their readers are familiar with and can relate to. Such language should at least be readable and comprehensible to the targeted readers. In the context of Ghana, this may be an important way of ensuring the comfort of readers.

\section{Conclusion: A case for the use of simple English in Ghanaian newspapers:}

It is important to end this paper with a caveat. The conclusions of this study are based on only a number of lexical and syntactic features and does not include some other text features or all the linguistic elements of text. Indeed, other linguistic features such as cohesion, collocation, coherence, noun phrases, among others, are alternative and complementary items that could serve as variables of inquiry for further research. Additionally, apart from Fosu (2014), few large-scale studies have attempted to discover empirically whether and to what extent (some) readers are challenged by the language of the press or otherwise. Therefore, this study should better be viewed as a contribution toward a holistic understanding of the problem in Ghana, for which reason further studies are required on the topic.

Nevertheless, the caveat does not in any way undermine or negate the findings of this study. Thus, results concerning the complex nature of the newspapers' language provide a reason to advocate the use of simple or plain language in Ghanaian journalism. It is normatively expected that news producers must use language consciously to connect with their audiences and through that demonstrate their knowledge and awareness of their audiences. Conboy (2007: 41) cogently expresses this linguistic dimension of journalistic practice thus:

Vocabulary of news attempts to appeal to a particular audience in terms of the register used. Register refers to the use of a particular type of language in a particular context. Register can reveal as much about the media institution as it can about its perceived audience because it circulates a version of the language of its targeted social grouping.

This perspective bears testimony to the positive appeal that using a language style that suits audiences has on readership. Drawing on Brian McNair, Conboy (2011: 119-120) observes that a shift in the language style of the elite press from pompous and erudite forms to a more user-friendly style (of the tabloid) illustrated a step "towards a more inclusive, even democratic journalism culture."

The practical usefulness of using simple language in news as indicated above is supported by the fact that journalism textbooks and news writing guidebooks (see for example, Harcup (2009) and Smith (2007)) promote simple writing styles. These 
studies on journalism devote chapters or sections to linguistic issues concerning lexical and syntactic usage to emphasise the importance and role of these linguistic elements in news comprehension. For example, Smith (2007: 120) provides the following caution:

- Use short words rather than long ones if they do the job just as well fire not conflagration, dead not deceased. People tell you what they saw, not inform you what they witnessed.

- Be active, not passive. Say people did something, not something happened to them.

- Be user-friendly. Don't say a sewage regeneration schemes planned when you mean families are going to get better drains.

This means that news writing is a kind of negotiation at both the writing and reading phases of the communication process. However, this study puts the responsibility more at the writing phase. Journalists ought to use simple and clear language to make otherwise complex topics, such as legal and governance issues, readable and easily comprehensible to audiences.

\section{References}

Adolphs, S. 2006. Introducing electronic text analysis. London: Routledge.

Akyeampong, K. et al.2007. Access to basic education in Ghana: The evidence and the issues, country analytic report. Published by the Consortium for Research on Education Access, Transitions \& Equity (CREATE).

Amankwah, A. S. 2010. A review of newspaper reading habits of residents of Adenta SSNIT Flats. Accessed 11 January 2013. Social Science Research Network. From: http://dx.doi.org/10.2139/ssrn.1655740

Amdur, R. J. et al. 2010. Use of the passive voice in medical journal articles. AMWA journal. 25(3): 98-104.

Ampiah, J. G. 2010. Quality basic education in Ghana: Prescription, praxis and problems. Paper delivered at the Experience Sharing Seminar, 17-19 January. Accra. From: http://aadcice.hiroshima-u.ac.jp/e/reseach/paper_no1-1.pdf

Anagnostou, N. K. and Weir, G. R. S. 2006. From corpus-based collocation frequencies to readability measure. In: ICT in the Analysis, Teaching and Learning of Languages. Accessed 29 June 2012. From: http://strathprints.strath.ac.uk/id/eprint/2381 
Anokwa, K. 1997. Press performance under civilian and military regimes in Ghana. In: Eribo, F. and Jong-Ebot, W. eds. Press freedom and communication in Africa. Asmara: African World Press. 3-28.

Ansah, G. N. 2008. Linguistic diversity in the modern world: Practicalities and paradoxes. The international journal of language society and culture. Issue 26. Accessed 14 May 2011. From: www.educ.utas.edu.au/users/tle/JOURNAL/issues/2008/26-1.pdf

- [no date]. Lexical creativity and national development: The case of Akan talk radio in Ghana. Accessed 29 September 2012. Lancaster University, UK. From: http://www.nai.uu.se/ecas-4/panels/141-156/panel-149/Gladys-Ansah-Full-paper.pdf

Ansu-Kyeremeh, K. \& Gadzekpo, A. 1996. Who reads the newspapers, why and for what? A Ghanaian readership survey. (Study conducted for the European Union Continuing Education for Media Education Project). Accra: School of Communication Studies, University of Ghana, Legon.

Ansu-Kyeremeh, K. \& Karikari, K. 1998. Media Ghana: Ghana media overview, practitioners and institutions. Legon, Accra: School of Communications Studies Press.

Asante, C. 1996. The Press in Ghana: Problems and prospects. New York: University Press of America.

Awedoba, A. K. 2001. Policy dialogue and classroom-based research on Ghana's school language policy. Accessed 12 May 2011. From: http://ddpext.worldbank.org/EdStats/GHAdprep01.pdf

Babbie, E. 2005. The basics of social research. California: Thomson Wadsworth.

Baumann, J. F. 2009. Vocabulary and reading comprehension: The nexus of meaning. In: Israel, S. E. and Duffy, G. G. eds. Handbook of research on reading comprehension. New York and London: Routledge. 323-346.

BBC World Service Trust. 2006. African Media Development Initiative: Research summary report. Accessed 20 June $2010 . \quad$ From: http://africanmediainitiative.org/content/2013/07/22/AMDI-BBC-summary-report.pdf

Biber, D. et al. 1998. Corpus linguistics: Investigating language structure and use. Cambridge: Cambridge University Press.

Biber, D. et al. 1999. Longman grammar of spoken and written English. Harlow: Pearson Education Limited.

Boafo, S. T. K. 1987. Democratising media systems in African societies: The case of Ghana. Africa media review. 2(1): 24-37.

Bourgault, L. M. 1995. Mass media in sub-Saharan Africa. Bloomington and Indianapolis: Indiana University Press.

Christians, C. G. et al. 2009. Normative theories of the media: journalism in democratic societies. Urbana and Chicago: University of Illinois Press.

Constitution of the Republic of Ghana. 1992. Accessed 15 March 2011.

From: http://www.judicial.gov.gh/constitution/chapter/chap_12.htm 
Conboy, M. 2007. The language of the news. London: Routledge.

-. 2010. The language of newspapers: Sociological perspectives. London: Continuum.

Dagut, M. \& Laufer, B. 1985. Avoidance of phrasal verbs: A case for contrastive analysis. Studies in Second Language Acquisition. 7, 73-79.

Daily Graphic. Accra: Graphic Communications LTD. From: http://www.graphic.com.org.gh.

Daily Guide. Accra: Western Publications Ltd. From: http://www.dailyguideghana.com.

Dale, E. \& Chall, J. S. 1948. A formula for predicting readability. Education research journal. 27(1): 11-20.

-. 1949. The concept of readability. Elementary English. 26(32).

- 1995. Readability Revisited: The new Dale-Chall readability formula. Massachusetts: Brookline Books.

Davies, M. 2009. The 385+ million-word corpus of Contemporary American English (19902008+): Design, architecture, and linguistic insights. International journal of corpus linguistics. 14(2): 150-190.

Denkabe, A. \& Gadzekpo, A. 1996. What is fit to print? Language of the press in Ghana. Accra: Ghana Universities Press.

Denkabe, A. et al. 1997. Extra-linguistic factors in the use of language in the Ghanaian press. In: English in Ghana. Accra: A Publication of the Ghana English Studies Association. 286-298.

Douglas, F. 2003. 'The Scottish corpus of texts and speech: Problems of corpus design'. Literary and linguistic computing. 18(1): 23-37.

—. 2009. Scottish newspapers, language and identity. Edinburgh: Edinburgh University Press.

DuBay, H. W. 2004. The principles of readability. Costa Messa, California: Impact Information.

Dzisah, W. S. 2008. News media and democracy in Ghana. PhD Thesis.

University of Westminster.

Eribo, F. \& Jong-Ebot, W. eds. 1997. Press freedom and communication in Africa. Asmara: African World Press.

Eveland Jr., W. P. \& Scheufele, D. A. 2000. Connecting news media use with gaps in knowledge and participation. Political communication. 17(3): 215-237.

Flesch, R. 1943. Marks of a readable style. In: Columbia University contributions to education. 897. New York: Bureau of Publications. 1-69.

—. 1948. A new readability yardstick. Journal of applied psychology. (32): 221-233.

-. 1949. The art of readable writing. New York: Harper.

-. 1951. How to test readability. New York: Harper.

Fosu, M. 2009. English in tertiary institutions and the issue of falling standards: Expectations, lessons and changes. Journal of communication, media \& society. 1(1): 22 -29.

- 2014. The press and political participation: Newspapers and the politics of linguistic exclusion and inclusion in Ghana. Unpublished PhD Thesis: University of Leeds. 
Fowler, R. 1991. Language in the news: Discourse and ideology in the press. New York and London: Routledge.

Gasu, J. 2009. The media and democracy in Ghana: The challenges of ensuring good governance. Journal of communications, media \& society. 1(1): 92-102.

Ghana Demographics Profile. 2012. Accessed 15 May 2011. From:

www.indexmundi.com/ghana/demographics_profile.html

Ghana Statistical Service. 2008. Ghana living standards survey: Report of the fifth round. $\begin{array}{llll}\text { Accessed } & 17 & \text { May } & \text { From: }\end{array}$ http://www.statsghana,gov.gh/docfiles/glss5_reports.pdf

- 2012.2010 population and housing census: Summary report of final results. Accra: Ghana Statistical Service.

—. 2013. 2010 population \& housing Census: National analytical report. Accessed 8 December 2016.2 From: http://www.statsghana.gov.gh/docfiles/2010phc/National_Analytical_Report.pdf

Ghanaian Times. Accra: New Times Corporation Ltd. From: http://newtimes.com.gh.

Guerini, F. (2007). Multilingualism and language attitude in Ghana: A

preliminary survey. $6^{\text {th }}$ International Symposium on Bilingualism, University of Hamburg, Germany. 29th May-2nd July. 1-33. Accessed 18 January 2011. From: http://www.ethnorema.it/pdf/numero\%204/03\%20Articolo\%20Guerini.pdf

Gunning, R. 1952. The techniques of clear writing. New York: McGraw-Hill.

Guo, Y. et al. 2011. The relation of morphological awareness and syntactic awareness to adults' reading comprehension: Is vocabulary knowledge a mediating variable? Journal of literacy research. 43(2): 159-183.

Harcup, T. 2009. Journalism: Principles and practice ( $2^{\text {nd }}$ Edition). London: Sage.

Hasty, J. 2005. The press and political culture in Ghana. Bloomington and Indianapolis: Indiana University Press.

Hess, K. \& Biggam, S. 2004. A discussion of "Increasing Text Complexity". Appendices for New England Common Assessment Programme (NECAP) Reading GLEs: Grades K-8. Accessed 21 October 2012. From: http://schools.nyc.gov/NR/rdonlyres/C89004883D92-4470-9A79-32CD81475D96/0/TextComplexity_KH05.pdf

Heydari, P. 2012. The validity of some popular readability formulas. Mediterranean Journal of Social Sciences. 3(2): 423-435.

Hudson, T. 2007. Teaching second language reading. Oxford: Oxford University Press.

Hulden, M. 2004. Linguistic complexity in two American newspapers and the Associated Press newswire, 1900-2000. Accessed 5 June 2012. From: http://dingo.sbs.arizona.edu/ mhulden/thesis-hulden_2004.pdf

Israel, S. E. and Duffy, G. G. eds. 2009. Handbook of research on reading comprehension. New York and London: Routledge. 
Just, M. A. and Carpenter, P. A. 1980. A theory of reading: from eye fixation to comprehension. Psychological review. 87 (4): 329-354.

-. 1992. A capacity theory of comprehension - individual-differences in working memory. Psychological review. 99(1): 122-149.

Kafewo, S. 2006. Ghana: Research findings and conclusions. African Media Development Initiative (AMDI). Accessed 25 January 2012. From: http://www.africanmediainitiative.org/upload/AMDI Report - Ghana.pdf

Karikari, K. 1998. The press and the transition to multi-party democracy in Ghana. In: Ninsin, K.A. ed. Ghana: Transition to Democracy. Dakar: CODESRIA. 189-210.

Klare, G. R. 1963. The measurement of readability. Ames, Iowa: Iowa State University Press.

-. 1984. Readability. In: Pearson, P. D. ed. Handbook of reading research. New York: Longman. 681-744.

Kleinnijenhuis, J. 1991. Newspaper complexity and the knowledge gap. European Journal of Communication. 6(4): 499-522. Accessed 2 April 1012. From: http://www.ejc.sagepub.com/content/6/4/299.refs.html.

Kletzien, S. B. 1991. Strategy used by good and poor comprehenders reading expository text of differing levels. Reading research quarterly. 26(1): 67-86.

Laufer, B. 1989. What percentage of text-lexis is essential for comprehension? In: Lauren, C. and Nordman, M. eds. Special language: From humans to thinking machines. Clevedon: Multilingual Matters. 316-323.

Laufer, B. \& Eliasson, S. 1993. What causes avoidance in L2 learning: L1-L2 difference, L1L2 similarity, or L2 complexity? Studies in second language acquisition, 15. 35-48.

Liao, Y. D. \& Fukuya, Y. J. 2002. Avoidance of phrasal verbs: The case of Chinese learners of English. Second Language Studies, 20(2): 71-106. From: http://www.hawaii.edu/sls/sls/wp-content/uploads/2011/06/LiaoFukuya.pdf

Loughran, T. \& McDonald, B. 2009. Plain English, readability and 10-K filings. Accessed 15 October 2012. From: http://www.nd.edu/ tloughra/Plain_English.pdf

Lu, X. 2010. Automatic analysis of syntactic complexity in second language writing. International journal of corpus linguistics. 15(4): 474-496.

-. 2011. A corpus-based evaluation of syntactic complexity measures as indices of college level ESL writers' language development. TESOL quarterly. 45(1): 36-62.

McEnery, T. \& Wilson, A. 2001. Corpus linguistics: An introduction. Edinburgh: Edinburgh University Press Ltd.

McEnery, T. et al. 2006. Corpus-based language studies: An advanced resource book. Abingdon, London: Routledge.

McLaughlin, H. 1969. SMOG grading: A new readability formula. Journal of reading. 22(4): 639-646. 
McNamara, D. S. et al. 2010. Linguistic features of writing quality. Written communication. 27(1): 57- 86. Accessed 16 March 2011. From: http://wcx.sagepub.com/content/27/1/57.refs.html

McNamara, D. S. et al. 2011. Comprehension challenges in the fourth grade: The role of text cohesion, text genre, and readers' prior knowledge. International electronic journal of elementary education. 4(1): 229-257.

McQuail, D. 1983. Mass communication theory: An introduction. London: Sage Publications. -. 2005. McQuail's mass communication theory. London: Sage Publications.

Ministry of Education and Sports, Ghana. 2010. Report on basic statistics and planning parameters for Primary, JHS and SHS Schools in Ghana. Accra: EMIS.

Nation, I. S. P. 1990. Teaching and learning vocabulary. Boston, Massachusetts: Heinle and Heinle Publishers.

- 2001. Learning vocabulary in another language. Cambridge: Cambridge University Press.

Nation, P. \& Coady, J. 1988. Vocabulary and reading. In: Carter, R. and McCarthy, M. eds. Vocabulary and language teaching. London \& New York: Longman Group. 97-110.

Nisbet, E. C. 2008. Media use, democratic citizenship, and communication gaps in a developing democracy. International journal of public opinion research. 20(4): 454-482.

Obeng, S. G. 1997. An analysis of the linguistic situation in Ghana. African languages and culture. 10(1): 63-81.

Owu-Ewie, C. 2014. Readability of comprehension passages in Junior High School (JHS) English Textbooks in Ghana. Ghana Journal of Linguistics 3(2): 35-68

- 2006. The language policy of education in Ghana: A critical look at the English-only language policy of education. In: Mugane, J. et al. eds. Selected proceedings of the $35^{\text {th }}$ annual conference on African linguistics. Somerville. M. A.: Cascadilla Proceedings Project. 76-85.

Pitler, E. \& Nenkova, A. (n.d.). Revisiting readability: A unified framework for predicting text quality. Accessed 11 November 2013. From: http://www.cis.upenn.edu/ nenkova/papers/revisitingReadability.pdf

Read, J. 2000. Assessing vocabulary. Cambridge: Cambridge University Press.

Readability Formulas. (n.d.). [Accessed 5 January 2012]. From: http://www.readabilityformulas.com/free-readability-formula-test.php

Redish, J. 2000. Usability testing reveals more than readability formulas reveal: readability formulas have even more limitations than Klare discusses. ACM Journal of Computer documentation. 24(3): 132-137.

Redish, J. C. \& Selzer, J. 1985. The place of readability formulas in technical communication. Technical communication. Fourth Quarter. 46-52.

Richards, L. C. and Rogers, T. S. 1986. Approaches and methods in language teaching: A descriptive analysis. Cambridge: Cambridge University Press. 
Rock, F. 2007. Communicating rights: The language of arrest and detention. Basingstoke: Palgrave Macmillan.

Russell, S. 2001. Grammar, Structure \& style: a practical guide to Advanced Level English language. Oxford: Oxford University Press.

Sanni, M. 1985. The readability levels of Nigerian newspaper editorials: A case study of The Guardian and the Daily Times. MA Thesis. University of Ibadan.

Scott, M., 2012. WordSmith Tools version 6, Liverpool: Lexical analysis software. From: http://www.lexically.net/wordsmith/index.html

—. BNC Wordlist. [no date]. From:

http://www.lexically.net/downloads/version4/downloading\%20BNC.htm

Sinclair, J. 1991. Corpus, concordance and collocation. Oxford: Oxford University Press.

Smith, J. 2007. Essential Reporting: The NCTJ guide for trainee journalists. London: Sage Publications.

Stahl, S. A. 2003. Vocabulary and readability: How knowing word meanings affects comprehension. Topics in language disorders. 23(3): 241-247.

Stenvall, M. 2011. Captured by convention. On objectivity and factuality in international news agency discourse. $\mathrm{PhD}$ Thesis. University of Helsinki.

Taiwo, R. 2007. Language, ideology and power relations in Nigerian newspaper headlines. Nebula. 4(1): 218-245.

Temin, J. and Smith, D. A. 2002. Media matters: Evaluating the role of the media in Ghana's 2000 elections. In: African affairs. 101. Royal Africa Society. 585-605.

The Chronicle. Accra: General Portfolio Ltd. From: http://ghanaian-chronicle.com.

The Dale-Chall 3,000 Word List. (n.d.). From: http://www.readabilityformulas.com/articles/dale-chall-readability-word-list.php

Tichenor, P. J. et al. 1970. Mass media flow and the differential flow in knowledge. Public opinion quarterly. 34(2): 159-170.

Turner, D. L. 1998. From classes to masses: A comparative study of the penny press and public journalism. Master of Art Dissertation. University of Ontario, Canada. From: http://www.collectionscanada.gc.ca/obj/s4/f2/dsk2/tape15/PQDD 0005/MQ30703.pdf

Yankson, I. K. et al. 2010. Reporting on road traffic injury: Content analysis of injuries and prevention opportunities in Ghanaian newspapers. Inj prev. 16. 194-197. Accessed on April 5, 2013. From: http://depts.washington.edu/hiprc/Newsroom/2010/Inj_Prev2010-Yankson-194-7.pdf 